\title{
Seeking the biotech eBay
}

\author{
Nuala Moran \\ Internet exchanges suggest an easy route to sourcing and licensing technology, but can biotech intellectual property \\ be packaged up and sold in this way?
}

$T^{\text {he }}$ here are sites for buying and selling most things on the internet, and intellectual property (IP) is no exception. The earliest of these IP exchanges sprang up at the height of the dot-com boom, when there was a rush to set up electronic marketplaces to ease business-to-business transactions of all sorts. Whereas selling paper clips and office stationery is one thing, it remains unclear-even a decade after the first IP sites were launchedif biotech patents and knowledge can be packaged, bought and sold in this way.

In the past few years, there has been a renewed effort to make this option practical. After all, startups, collaborations and partnerships are the engine of the biotech industry, and each involve IP transactions of some sort. At the same time, there is now an imperative to translate publicly funded research into economic growth, which has increased pressure on the technology transfer offices of universities and other research institutions to patent any resulting discoveries and find new ways to market them.

The first IP sites were set up by large corporations in such sectors as electronics, software and chemicals to allow companies to trade discoveries from their in-house research departments that they did not intend to exploit themselves. But other IP exchange sites have since been established by universities as a new avenue for technology transfer. Many of these sites, in both Europe and the United States, are financed by public or charitable funding in support of innovation policies. Given that such a high proportion of public funding goes to life sciences, most of these sites carry biotech-related IP.

\section{How do IP exchanges work?}

There are several different approaches to showcasing IP on the internet (Table 1).

Nuala Moran is a freelance writer based in Cheshire, UK.
Typically, technology transfer offices list technology available for licensing on their own website. But an increasing number of sites aggregate offerings from several institutions. Such sites basically operate as dating agencies - they are places to find technology and to express your interest to its owner. Some are free to use, whereas others charge subscription fees. The level of sophistication in terms of uploading and searching information varies from site to site, as does the level of customer support.

There are also third-party sites (particularly in the United States) that go one step further and try to help foster the actual transaction, allowing entrepreneurs to not only find intellectual property but also buy the rights online. Some of these sites will also provide brokers to act as intermediaries.

Biotech IP comes in many shapes and sizes, and some types are more amenable than others to being sold online. These are generally tools of some sort, and include materials, biomarkers, animal models and bioinformatics software. For commoditized products such as these, standard licenses can be filled in and processed online. However, most biotech IP is far more complex to use, apply and commercialize, and it cannot be packaged neatly in this cookie-cutter way.

One recent trend has been the consolidation of different IP exchange sites, as demonstrated by the recent agreement between B-Bridge Technology Transfer (Mountain View, California), which has mainly American and Japanese users, and the European site Innoget (Barcelona, Spain). Last October, the two said they will provide full access to each other's websites. The demand from users for one-stop shopping makes further consolidation likely.

\section{Gauging effectiveness}

The idea of an eBay for IP, where it would be possible to locate goods and buy them, seems attractive. But those with experience in the biotech industry doubt whether life science IP can be parcelled up and sold like old baseball cards or a bicycle.

Glyn Edwards, CEO of Antisoma (London), says his company "might use [IP exchanges] to look for stuff" but admits it is "not a perfect market." The company has spent more than a decade building up its network of personal contacts and combing the world's publicly funded research bodies for IP to in-license. Edwards says this particular skill is where a lot of his company's value resides, adding that Antisoma is "well-networked, and we know the people." Edwards believes Antisoma gets access to research findings at an early stage through this networking.

Tom Hockaday, managing director of Isis Innovation, the technology transfer arm of Oxford University, agrees that the exchanges work best as a shop window. Although Isis does list technology for sale, it uses only exchange services that are free. "It lets people know you are out there as a source of opportunities," says Hockaday. "But if we're required to pay, we won't do it. That's a commercial decision; we exist to market [Oxford University's] technology-that's what we are good at, so we don't pay anyone else to do it."

Hockaday adds that his organization sells early stage technology, which means it "needs work to get it to market." That points to a problem: in general, when a technology is in-licensed, tons of data need to be assimilated and know-how acquired to make the technology successful. That ancillary material and knowledge is not guaranteed when in-licensed through an exchange site.

Besides, Hockaday says, "we want to know the development plans of people taking on our technologies." In biotech, there is a long path from the university lab to the market. Typically, Isis and its counterparts don't get 
paid for technology-instead, they take an equity stake or are entitled to development milestones. In situations like that, it's important to know how the licensee intends to take a project forward and that there is funding to do so.

Like Hockaday, others want a personal relationship with the partners they are trading IP with. On the sell side, this means knowing there is a credible development plan, and on the buy side it means knowing that the expertise required to make the technology function will be on hand.

Another issue is negotiations-what is paid and when, including up-front payments, clinical milestones, research costs, royalties on sales and so forth. This generally cannot be conducted over exchange services. Most sites are only as sophisticated as having a buy or don't buy option.

Additionally, even with a platform technology or a drug target, there are many different ways of slicing up rights_-dividing them by geography and markets, by different indications or by usage (say, as a research tool or a diagnostic). This involves complex negotia- tions. For example, if you are taking rights in one region, it is important to know who has the license in another. If you want to develop a product in one disease area now, and you are successful, will you have the freedom to move into other indications in the future? IP exchanges offer a one-size-fits-all approach that, as yet, cannot handle these subtleties.

Justine Lalonde, an executive at F. Hoffmann La-Roche's Pharma Partnering Group (Basel, Switzerland), says her company doesn't use IP exchanges, though they do use a subscription drug discovery and development database to check out the compounds of potential partners or assess the competition in particular areas. A business development and partnering specialist at another large pharmaceutical company gave a similar response. Although pharmaceutical companies are more and more reliant on partnering with biotechs to fill their pipelines, IP exchanges are not seen as the place to go courting.

Another factor is time, according to biotech executive and investor Danny Green, former CEO of the startup BioCeramic Therapeutics (London), who remains a director of the com- pany. "The CEO of a young startup doesn't have the time to go searching on exchanges," he says. "You should look to a specialistit's important to stick to your priorities and not to spend time thinking about something when other people out there are experts."

Green is not alone in reaching this conclusion. Five other biotechs asked for their views on the value of IP exchanges in partnering say they do not use them. The reservations about the value of these sites are shared across the industry, from technology transfer offices and startups to more mature biotech and pharmaceutical companies. Everyone can understand the appeal of an eBay for biotech, but as yet no single exchange provides that critical mass. And biotech IP is not old junk from the garage-in general, it cannot be photographed. Instead of being a tangible object, IP usually consists of immense data files that require insight and know-how if anything is to be extracted from them or any value built around them.

There is also a general disdain over what type of material gets posted. Given the protective nature of the biotech industry, some

\section{Table 1 Selected websites offering IP that include life-science technologies}

URL

http://www.b-BridgeTechnologies.com/

http://www.ibridgenetwork.org/

http://www.innoget.com/

http://www.switt.ch/

http://www.university-technology.com/

http://www.tynax.com/

http://www.knowledgeexpress.com/

http://www.TechTransferonline.com/

http://www.theintellectualproperty.net/

http://www.yet2.com/

http://www.flintbox.com/

\section{Description}

This site provides a searchable database. More information can be obtained by posting messages to IP owners on a private bulletin board. The site, which launched in April 2009, lists technology from US and Japanese universities.

This site lists 10,820 technologies from 104 organizations, mainly US universities. There is an online licensing facility that provides the ability to enter into licenses with research labs directly from the site. Although the not-for-profit site, sponsored by the Kauffman Foundation (Washington, DC), covers all technologies, it has a high number of biomedical, biotech and drug discovery listings.

This site advertises itself as a portal for open innovation. As well as listing and requesting technologies, users can also pose challenges or problems for which they are seeking answers. Users pay an annual fee for listing and requesting technologies, but posing a challenge is free. The Spanish site offers a telephone support line.

This free-to-use site run by the Swiss Technology Transfer Association (Basel, Switzerland) lists technology for hire from universities across Switzerland.

This site carries IP listings from 13 Scottish universities across all fields of technology. Expressions of interest are passed on to the relevant institution, but for some technologies it is possible to fill out a standard license form online.

This full-service trading exchange charges no fees but takes a commission on completed deals. It features more than 10,000 patents and technologies and brokers transactions via a network of agents and its own staff at its headquarters in Silicon Valley.

This site is run by the information services company UTEK (Tampa, Florida) and provides access to a range of technology listings and patent databases. The subscription fee ranges from $\$ 7,950$ for a single user to $\$ 100,000$ for a global license. It incorporates another former exchange site, TechEx.

This site lays claim to the world's longest list of IP, with 95,000 technologies available for sale or license. Although there are no fees to list IP, there is an annual fee of $\$ 250$ to view listings. Technology owners are alerted every time their technology is viewed and can contact the viewer regardless of whether the viewer expressed an interest.

This site is run by Manchester University Intellectual Property and is funded by the Northwest Development Agency with backing from corporate sponsors. The site, which is free to use, went live in December 2009 and has listings from 20 UK universities. Currently, it is operating on a modest scale, with 400 technologies on offer and 5 requests for technologies listed.

This site was set up by corporate heavyweights including Dow Chemical (Midland, Michigan), DuPont (Wilmington, Delaware), Monsanto (St. Louis) and 3M (St. Paul, Missouri) at the height of the dot-com boom in 1999. It claims to represent over $42 \%$ of the world's R\&D capacity. The site has more than 100 registered users.

This site was set up in 2003 by UBC Research Enterprise, the technology commercialization arm of the University of British Columbia. Most of its listings and users are from North America, though it does have some in Denmark. The site offers three grades of membership at fees of $C \$ 600$ (US $\$ 568$ ), $C \$ 2,400$ (US $\$ 2,272$ ) and $C \$ 5,000$ (US $\$ 4,733$ ). In November 2009, the website was acquired by Wellspring (Pittsburgh), a supplier of software that enables technology transfer offices to manage and market IP. As a result, starting in May 2010, it will be free for users to post technology on the site, and Wellspring is also promising to incorporate new features. 
suggest that the IP listed on these websites as technology for hire has been turned down by industry leaders-in other words, advertising technology is a desperate move. As BioCeramic's Green puts it, the material posted has already been "hawked around."

\section{Looking forward}

Perhaps IP exchanges will build enough critical mass to replace existing channels. Chris Haley, marketing services manager of Imperial Innovations (London), has assessed 15 or so IP websites. Imperial Innovations is interested in such exchanges from the perspective of both out-licensing technology from its parent institution, Imperial College London, and building up the IP foundations of its spin-out companies. He says there are "more and more appearing, and my overall view is they potentially could be good [routes for out-licensing]."

In particular, he pointed to the London Technology Network, which carries listings of technology available for licensing from institutions in the city. The site is attractive because it is publicly funded through London's regional development agency and is free to use.

The IP exchanges do have another potential use: as an avenue for startups to explore or locate related technology. One patent alone is not sufficiently attractive to gain funding, and using exchanges to pool technologies could strengthen the portfolio and allow a startup to make a more compelling case to investors. However, even in that preferred route, exchanges might be helpful but not essential.

It's likely that IP exchanges could shape up to be a passive channel, enabling companies to off-load technology they do not have the resources to develop in-house. But perhaps the most important aspect of IP exchanges thus far is the way they have opened up the market for small and medium enterprises (SMEs), says Mark Thompson, head of market development at the University of Manchester Intellectual Property. "The big companies have people to [scout for interesting technology]. SMEs don't have the time, or much idea of how, to access technology coming out of universities."

In fact, after an 18-month pilot involving 30 universities and more than 100 companies, University of Manchester Intellectual Property launched last December what it claims is the first free-to-all technology trading portal. "This is the first system available which is suitable for SMEs to use to either market their technology or seek out innovations. It's as easy to use as sites such as eBay but is of course free," says Thompson. He's encouraged that SMEs are starting to use the site, and he is planning more marketing to attract them.

Exchange sites do have the benefit of being discreet. There are times when a bioentrepreneur needs to add value by acquiring rights to a particular piece of IP property but, for competitive reasons, does not want to advertise that fact. IP exchanges offer a way of quietly accessing a technology. This can be done without letting the seller know the reasons for your interest or the potential value of the IP. And it can allow companies to make a pre-emptive strike, acquiring rights to a technology to block a competitor.

\section{Conclusions}

There is widespread appreciation of the potential of buying and selling IP on the internet. Those who have tested these sites are generally sellers rather than buyers. But there is a feeling on both sides that biotech IP is not amenable to being packaged and sold. Despite these reservations, no one dismisses IP exchange sites out of hand: it's clear they provide a way for users to locate technologies and get a sense of what is actually out there. In fact, most think they will become more useful over time, given some consolidation and a greater number of users.

If the websites are to work, most feel they would be most useful for buying and selling some categories of technology, such as materials, culture media, mouse models of diseases or biomarkers-areas in which the product is relatively simple, the rights are not exclusive and one size fits all.

Although networking and personal contacts are at the heart of in-licensing, IP exchanges should be an increasingly important tool. "I would definitely keep an eye on these exchanges," says Imperial Innovation's Haley. "There's no obvious eBay out there yet, but if someone could crack it, that would enhance their value."
To discuss the contents of this article, join the Bioentrepreneur forum on Nature Network: http://network.nature.com/groups/bioentrepreneur/forum/topics 